\title{
Fast Filter for In Vitro Studies
}

\section{DONALD R. DIETZ AND HAROLD E. MESSNER}

Highlight: $A$ crucible for filtering plant material is made by modifying an aluminum $35-\mathrm{mm}$ film canister to hold the filter, composed of glass wool fiber and nylon curtain mesh. Cleaning and preparation of the canister for a new test is simplified by disposing of the used filter and inserting a new one. Comparison with sintered glass crucibles showed no significant differences in in vitro digestible dry matter values.

The technician conducting in vitro digestion tests is often exasperated by slow or clogged filters. The original Tilley and Terry (1963) method called for filtration through a $12.5 \mathrm{~cm}$ disc of Whatman $^{1}$ filter paper No. 4. After experiencing difficulty in filtering with this method, we tried various others.

The method outlined by Martinez and Church (1970) used a glass crucible with fritted glass disc. Pearson (1970) performed his filtration with a glass fiber filter paper. Kamstra (1972) recommended a polypropylene test tube in which he removed the liquid portion of the sample by first centrifuging to pack the solid material, and then vacuum filtering off the supernatant. When we tried these methods, they all had shortcomings as well as certain advantages. These are described in the discussion section.

This article describes a new "fast filter" we designed after considerable trial and error.

\section{Materials and Methods}

We established several important criteria in our search for materials to construct a "fast filter." The crucible should be (1) easy to make, (2) durable, (3) constructed of readily available material, (4) easy to clean, and (5) possibly most important-capable of maintaining a constant weight (i.e.,

Authors are principal wildlife biologist and range technician, Rocky Mountain Forest and Range Experiment Station, Forest Service, U.S. Department of Agriculture, Rapid City, South Dakota. Dietz at present is fish and wildlife biologist, Fish and Wildlife Service, U.S. Department of Interior, Grand Junction, Colorado.

Research reported here was conducted at Rapid City in cooperation with South Dakota School of Mines and Technology. Station's central headquarters is maintained at Fort Collins in cooperation with Colorado State University.

Manuscript received February 5, 1975.

${ }^{1}$ Trade names are used for the benefit of the reader, and do not imply endorsement or preferential treatment by U.S. Department of Agriculture.

Crucible Components:

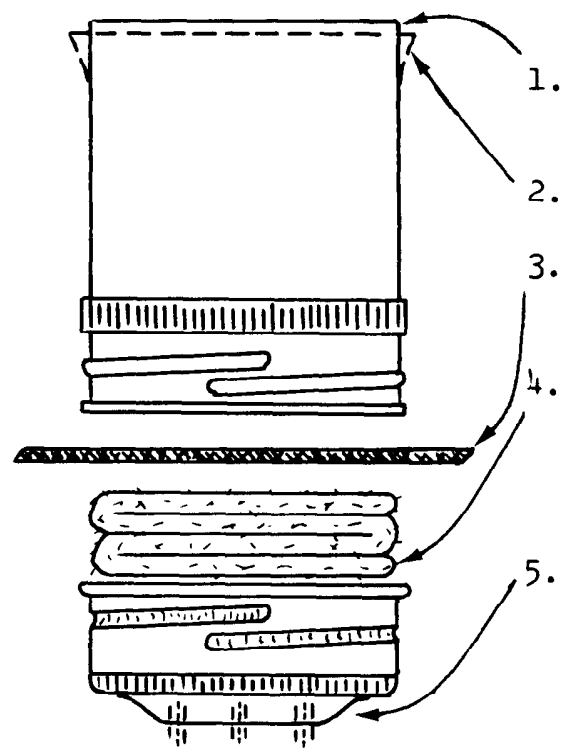

Bottom of canister is cut off to make top of filter.

Top of filter flaired.

$5 \mathrm{~cm}$. square piece of nylon curtain mesh.

$10 \mathrm{~cm}$. square of fiberglass wool folded 4 times and pressed down in bottom. (About $0.75 \mathrm{g.}$ )

Top of canister becomes bottom of filter. The rubber seal is removed and five $1 / 16^{\prime \prime}$ holes are drilled through top of lid.

Fig. 1. Components used in the construction of "fast filter" from aluminum $35 \mathrm{~mm}$ film canister.

resist rapid moisture absorption after removal from a desiccator). These criteria were met by modifying a $35 \mathrm{~mm}$ aluminum film canister to hold a glass wool fiber filter.

\section{Construction of "fast filter"}

The basic materials used in construction of the crucibles are:

- Aluminum $35 \mathrm{~mm}$ film canisters with lids (canisters are approximately $32 \mathrm{~mm}$ in diameter and $50 \mathrm{~mm}$ tall).

- Nylon curtain mesh (approximately 64 threads per inch) obtainable at most fabric shops.

- Glass wool fiber. We used Pyrex brand wool filtering fiber. ${ }^{1}$

Crucibles were constructed in the following steps (Fig. 1):

1. Cut bottom out of $35 \mathrm{~mm}$ aluminum canister and smooth rough edges. This now becomes top of crucible.

2. Flare out top to provide larger diameter for receiving material from digestion tubes. We used the neck of a soft drink bottle to flare tops.

3. Remove rubber seal from inside the screw lid. Flatten the peak of the lid to provide a flatter surface when filling, filtering, and weighing.

4. Drill five 1/16-inch holes equally spaced in screw lid. File rough edges.

5. Place a piece of glass wool about $10 \mathrm{~cm}$ square by 2 or $3 \mathrm{~cm}$ thick (roughly $0.75 \mathrm{~g}$ ), folded about four times into bottom of lid. Secure by pressing firmly with fingers.
6. Place a $5-\mathrm{cm}^{2}$ piece of nylon curtain mesh over the glass filtering fiber, and screw the lid on to the canister. The nylon cloth should now be tightly stretched over the glass wool fiber and between the lid and body of the canister. Trim off all excess nylon cloth. Number by inscribing with ballpoint pen on soft aluminum sides.

7. Crucible is now ready to use as a filter. Place a section of light, stretchy rubber tubing over the threaded connection of canister to lid to make air-tight (Fig. 2). We cut 1-inch sections out of fingers of old surgical

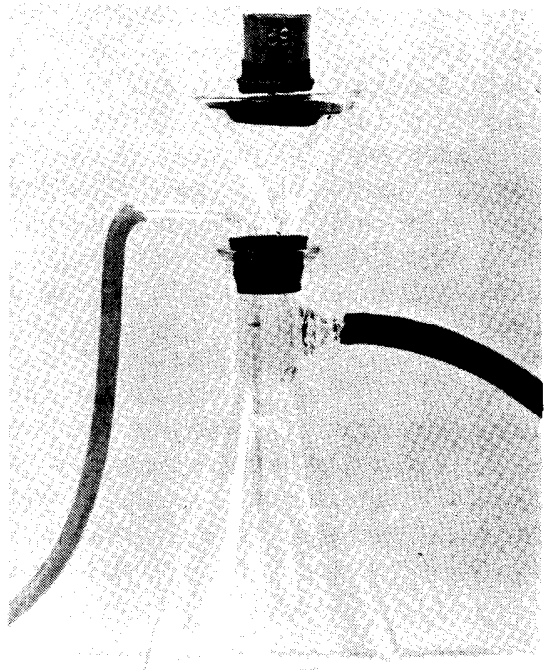

Fig. 2. Filtering process with fast filter seated in glass funnel. 
gloves for this purpose. Remove rubber sleeve before drying and weighing.

8. Suction is applied by attaching the crucible to a vacuum apparatus. This was done by inserting a glass funnel through a rubber stopper and placing it in a filtering flask. The crucible was seated in the funnel by placing it in a rubber collar. The flask was connected to a vacuum pump.

\section{Testing and Filter}

The first step in testing the new filter was to see if precise dry weights could be obtained readily and, more important, if these values could be repeated after many weighings and dryings. After we were satisfied that weights varied only minimally, the next step was to monitor the "fast filters" to see if any solid materials could work through the fiberglass mat. In no case had particles penetrated more than $1 \mathrm{~mm}$ into the mat, which is $5-6 \mathrm{~mm}$ thick.

The final check was a comparison of the "quick" filters with fritted glass crucibles. Triplicate samples of plant material from serviceberry (Amelanchier alnifolia), aspen (Populus tremuloides), and Woods rose (Rosa woodsii) were placed into $100-\mathrm{ml}$ polypropylene test tubes arranged at random in an in vitro digestion apparatus. The plant material had first been air-dried and ground through a Wiley mill to pass through a $1-\mathrm{mm}$ mesh screen. Blank samples were also prepared in triplicate. In vitro digestion procedures, as described by Tilley and Terry (1963), were performed using inoculum from two white-tailed deer. The triplicate samples and blanks were filtered through both types of filters during both digestion trials.

The means and standard deviations for digestible dry matter (plant species and deer combined) were $53.79 \pm$ $1.60 \%$ for the glass filters and $55.69 \pm$ $2.86 \%$ for the aluminum filters. This difference of 1.90 percentage points was not significant at the 0.05 alpha level when compared by a paired $t$-test $\left(t_{7 \mathbf{d f}}=0.229\right)$. The glass crucibles gave somewhat better precision, having a sampling error within $2.97 \%$ of the mean; however, sampling error was within $5.13 \%$ of the mean for the aluminum filters. It was not possible to determine the relative accuracy of the two filters since both employ empirical methods. The fritied glass was slower (from 2 to 3 times) with
Imost all samples.

\section{Proper Technique for Using Filter}

To make the most efficient use of the "fast filter" the proper technique must be employed. First, the canister must be securely seated in the rubber collar of the funnel at about a $60^{\circ}$ angle. The sample should not be agitated before or while pouring gently onto the sloping inside wall of the canister. Heavy materials will tend to collect on the lower part of the fiber mat while the clearer supernatant solution will flow rapidly through the upper part of the filter pad. If the sample slows or stops filtering, one should wait until that portion filters through and then rinse with hot 95\% alcohol. This will dissolve some of the gums, etc. blocking the filter material. A clogged filter can be unclogged by transferring the crucible from the filtering apparatus to a bcaker. Hot alcohol or acetone and gentle scrubbing with a rubber policeman will usually break up the clogging agent. Re-heating the remainder of the solution prior to pouring back into the canister and frequent washing of the filter mat with hot alcohol will often permit completion of the filtering.

\section{Discussion}

Many filtering systems were tried before we designed the filter made from an aluminum film canister. Although each filter tried had certain advantages, they had enough disadvantages filtering our material to encourage the development of a faster system. In brief the principal problems with the others, besides being slower, were that glass filters broke easily and were difficult to clean, while the paper and glass fiber filters and polypropylene test tubes were either difficult to weigh and/or to maintain precision between weighings. The advantages and disadvantages of the "fast filter" are:

A. Advantages:

1. Fast filtering.

2. Disposable filter material.

3. Accuracy and precision good.

4. Easy to handle, unbreakable.

5. Readily obtainable, inexpensive to build, and casy to number.

\section{B. Disadvantages:}

1. Must be hand constructed.
2. Preparation and insertion of filter pad is time consuming.

3. Filter material more expensive than paper filters.

4. Filter cannot be ashed to measure organic matter digestibility.

We experienced some difficulty with rust forming on the metal lid (which is not aluminum) of the crucible in and around the drilled holes. Rust can be prevented by dipping the lid in acetone before drying the filter with residue in the oven.

Van Soest et al. (1966) discussed residues obtained by the Tilley and Terry (1963) method. These authors suggest that certain bacterial residues retained on filters finer than coarse sintered glass or sintered glass covered with a filter aid tend to lower the resulting in vitro digestibility values of dry matter.

With our "fast filter" we usually obtained a slightly greater weight of residual material from the blanks than was obtained with coarse sintered glass crucibles. Digestibilities obtained with the forage samples were slightly higher (nonsignificant at $\alpha=0.05$ ) for the aluminum canister than for the sintered glass crucibles. In the comparison tests, the "fast filters" retained 1.84 percentage points more blank residue than the fritted glass, and showed a mean dry matter digestibility of 1.90 percentage points more. These differences are not significant at the 0.05 alpha level. We therefore believe the "fast filter" will expedite the determination of digestible dry matter, especially for those materials which are slow to filter.

\section{Literature Cited}

Kamstra, L. D. 1972. Personal correspondence. Prof. Anim. Sci., S. Dakota State Univ., Brookings.

Martinez, A., and D. C. Church. 1970. Effect of various mineral elements on in vitro rumen cellulose digestion. J. Anim. Sci. 31:982-990.

Pearson, H. A. 1970. Digestibility trials: in vitro techniques. In: Range and wild life habitat evaluation symp. U.S. Dep. Agr. Misc. Pub. 1147. p. 85-91.

Tilley, J. M. A., and R. A. Terry. 1963. A two-stage technique for the in vitro digestion of forage crops. J. British Grassl. Soc. 18:104-111.

Van Soest, P. J., R. H. Wine, and L. A. Moore. 1966. Estimation of the true digestibility of forages by the in vitro digestion of cell walls. Proc. 10th Internat. Grassl. Cong. p. 438-441. 